\title{
The Role Played by the Family in Contributing or Abating Juvenile Delinquency in Schools
}

\author{
Philip Gazimbe*, Tungu Mufunani Khosa \\ Faculty of Education: Zimbabwe Open University \\ *Corresponding Author: Philip Gazimbe, Faculty of Education: Zimbabwe Open University
}

\begin{abstract}
For children, family is the major source of companionship, affection and reassurance. The nature of the relationship between parents and their children helps to determine whether a child becomes a delinquent. Affectionate, supportive, and understanding homes are likely to promote conformist and constructive social behavior, because a positive family environment leads to healthy personality development. Conversely, a lack of parental affection and support, or in more severe cases parental indifference, hostility or rejection, causes children to feel emotionally insecure and leads to poor personality development, thus encouraging antisocial or delinquent behaviour. Negative parental attitudes often include scolding and a lack of love. Another negative attitude is that of authoritarian parenting, where excessive control, using harsh and strict commands, deprives children of the freedom to express themselves. The suppression of free expression and an absence of love encourage children to revolt against their parents, to run away from their families, and consequently to enter a life of crime. Negative parental attitudes, including concealing information or failing to respond to questions, have been shown to induce feelings of emotional and social insecurity in children. Such insecurity can degenerate into children developing mental problems, or can lead to delinquent behavior. This paper attempts to expose the role played by the family in promoting juvenile delinquency in schools.
\end{abstract}

Key words: Role, juvenile delinquency, family, secondary schools, parents

\section{INTRODUCTION}

The concept of family has received a variety of definitions, because families vary greatly in their sizes and constituent parts. These various types of family accomplish different things for their family members. Mapp (2009) defines a family, as a group of people held together by common birth, marriage, residence, close emotional attachment or adoption, while for Desai a family means a unit of two or more persons united by blood, marriage, adoption or consensual union who interact and communicate with each other. Families may also include people with common ancestors, as part of a lineage, clan or tribe. UNESCO (2014) broadly defines a family as being a social reality, although the kinship unit and members do not have to share a common household. Although there are a number of differences in the types of families found in the world, they have certain things in common. For example, families serve several important functions within society, including socialization, economic support, nurturing, protection of vulnerable members, and perpetuating the family grouping. In general, despite differences between cultures, families serve the three basic goals of economic selfsufficiency, improving family circumstances and perpetuating their existence. The traditional concept of family includes responsibilities and functions such as intimacy and affection, security, childbearing and child-rearing(Simons et al. 1991). Traditional family tasks include assigning roles, assuring social interaction between family members, providing physical care, allocating resources, maintaining morale and motivation and relating to external society and its institutions. Increasing rates of divorce and remarriage have led to the emergence of reconstituted families (stepfamilies), which represent households containing a child or children who are biologically related to only one of the adults. Changes in the social environment often require adaptations in family structure and functioning.

\section{FAMILY BACKGROUND}

The family can be regarded as the micro social environment of children because it is from the family that one is socialised into norms, values, beliefs, and customs of society before one is exposed to the world outside the home, the community. The family is hence pivotal in shaping the character of the 
growing child. In this part of the study dealing with the family as inherently linked to delinquency causal factors, the following themes will be discussed: family economic status, family structure, family control and supervision and family religiousness. The family is arguably the most critical agent of socialisation for humankind. Language norms, values and beliefs are inculcated to children at a tender age, right through the adolescent period right to adulthood. Thus, the family has a powerful influence on the personality and character of its family members. External influences on the character of an individual cannot be downplayed but it is the family which has the initial and long lasting influence on family members. A family will therefore, bequeath its values to its offspring - whether they be positive or negative.

Findings of a study by Mapp (2009) in the United States show that attendance of religious services is negatively and significantly associated with arrest, light and heavy crime, and marijuana use. The research findings revealed that religious affiliation, importance of religion and importance of spirituality were all negatively and significantly associated with marijuana use. Since the family provides the child with religious socialisation, it is apparent that the family background is critical in influencing a child's behaviour. Thus, a family which takes the children to church service may cause the adolescent to avoid drug abuse and related delinquent conduct.

The influence of the family is also highlighted by Nisar et al. (2015). They posit that delinquency is not caused by a single factor but by a combination of factors, which include the family as the predominant factor. Nisar et al. (2015) pointed out that some parents give poor directions to children. In addition, the parents fail to control children's behaviour and fail to appropriately reward or punish the children. They posit that children from poor and working class backgrounds are much more likely to engage in delinquent behaviour. It would be interesting to find out in the current study the kind of family background the delinquent juveniles come from, such findings would provide the basis for comparison of causal factors.

Roberts (2002) asserts that children exposed to behavioural problems and family dysfunction started off with manifestations such as defiance of adults, lack of school readiness and aggression towards peers. The condition would lead to teacher rejection, low academic achievement and involvement in drugs and alcohol. Such children would degenerate to eventual dropout, delinquency, violence and adult criminality. Cashwell (1996) in Nisar et al. (2015) says the coercion theory suggests that family environment influences an adolescent's interpersonal style; he argues that parental monitoring and disciplining have a bearing on the adolescent's association with deviant peers.

Smith (1997) in Nisar et al., (2015) found that parental conflict and parental aggressiveness predicted violent offending. Thornberry et al. (1999) posit that children who live in homes with only one parent or in which marital relationships have been disrupted by divorce or separation are more likely to display a range of behavioural problems including delinquency, compared to children from two parent families. Some of the juveniles in the current study have parents in the diaspora; it will be of interest to find out whether what has been stated above with regards to the role of the family also applies to the juveniles in Gweru secondary schools. Klein (1997) in Nisar et al. (2015) pointed out that two parents were much more effective in supervision of adolescents compared to one parent whose inadequate supervision could result in delinquent behaviour. The importance of the influence of the family on the juveniles is also highlighted in a study in Bahrain by Alnasir and Al-Falaij (2016). One of their findings was that family conditions could determine whether or not a young male was at risk of having delinquent behaviour and ultimately being convicted as a juvenile offender.

Stattin (2000) in Nisar et al. pointed out that monitoring of children's behaviour was very important to parenting and affected many areas of children's development. Research findings suggest that support from parents bonds the adolescents to institutions and builds their self-control. Self-control is said to hinder deviant behaviour from forming. Parents' effective use of discipline is said to prevent deviant behaviour from manifesting, parents do so by monitoring the behaviour of their children and apply problem solving techniques. Harsh punishment on the other hand does not stop misbehaviour but will enhance it (Simons et al. 1991). Monitoring children entails knowing where the child is, who the child plays with and what children do in their spare time. A study conducted by Barnes et al. (2006), in Carlson, found that monitoring is a strong predictor for adolescent deviant behaviour after peer deviant behaviour was controlled for. Parents' involvement in their child's behaviour is therefore very important. Parents' ability to communicate with their children makes children accept responsibilities and reduce their anger; this tends to reduce association with deviant peers. 
Simons et al. (1991) in Carlson argue that coercive parenting exacerbates negative traits influencing delinquency. Threatening behaviour and lack of consistency is not helpful, supporting the child's prosocial behaviour brings about improved behaviour. According to the strain theory, individuals indulge in deviant conduct because of their inability to achieve positively valued goals (Barnes et.al.). A child's valued goals include being loved and supported by a parent. When children fail to get this support they tend to experience anger and frustration, which tends to lead to deviant behaviour. Coercive parenting which consists of low monitoring and support and ineffective discipline coupled with harsh punishment, is said to influence deviant behaviour among adolescents (Robert, 2002). If the parent-child bond is weakened through conflict, the child tends to externalise their problems. Externalising troubles leads the adolescent to deviant conduct.

Amato and Cheadle (2008) in Carlson explain that divorce causes direct stress to a child. Divorce decreases the quality of parenting, weakening the bonds between the child and the parent. Weakened bonds result in lack of self-control by the adolescent who in turn acts out and engages in deviant behaviour. Divorce forces the adolescent to live in two separate households, weakening the child's bonds to each parent (Dornbusch, Carlsmith, Bushwall \& Ritter, 1985; Chowdhurry et. al., 2016). Adolescents living in families experiencing divorce or economic hardships experience lower levels of parental attachment and supervision and hostile family environments (Krohn, Hall and Lizotte, 2008) in Carlson. Social control theory assumes that two parents are better able to provide affection and supervision to their children than single parents (Mack et al., 2007).

The current study will also try to find out the influence of family background on the secondary school students in the selected schools in Gweru District in order to find out whether previous findings could also be true in the Zimbabwean situation, in Gweru District. The above research findings suggest that inadequate parental supervision predisposes adolescents to delinquent conduct. All research findings referred to above have aptly underscored the critical role that parents play in the upbringing and socialisation of the child. After discussion of research findings on the role the family plays in moulding the behaviour of the adolescent, I now focus on whether juvenile delinquency can be curbed in the secondary schools of Zimbabwe.

\section{FAMILY ECONOMIC STATUS}

Many researchers have noted that a family's poor socioeconomic background is a structural disadvantage that decreases the ability of a family to be in complete charge of its members (Sampson \& Laub, 1994: 523). Chowdhurry et al. (2016) posited that basic needs drove juveniles to engage in antisocial activities. The study noted that more than 6.5 million people lived under poverty line in Bangladesh. As a result, children resorted to crime in order to satisfy their needs. The findings from Sahmey's (2013) study include the following underlying causes of delinquency: insufficient resources for human sustenance; this is associated with economic uncertainties because poverty tends to push one into a world of crime. The study further established that low parental wages caused the children to commit offences. Parental neglect was also considered a strong factor; this was indicated in the case study reports. The other causal factors were due to poor surroundings. Similar arguments are put forward in Hulela and Matsolo's (2011) study when they noted that lack of material support, in addition to other factors, contributed to the delinquency of children. Alnasir \& Al Falaij's (2016) study also pointed out that the socioeconomic status of the family was related to the development of delinquency in juveniles. Chesney-Lind and Sheldon's (2014) study also concurs that youths of low socioeconomic status tended to be involved in serious delinquent acts compared to those of a better socioeconomic status. Juveniles needed to be loved and provided with basic necessities (Chowdhurry et al, 2016). Low income by parents created poverty. The juveniles who found themselves lacking in basic needs got involved in antisocial activities in order to fulfil their essential basic needs (Uddin, 1995). Uddin's study found that 70 percent of the juveniles under study were driven into delinquency because their families failed to provide them with basic needs; they therefore resorted to illegal means to obtain what they desired. Results from a case study of incarcerated juvenile offenders found that the main cause of their delinquent acts was neglect from family and poverty (Nisar et al.. 2015). Research findings in Nisar et al.' (2015) study showed that the major cause of juvenile crime was lack of education and low economic status. They reported that the main causes of juvenile delinquency are a family's low income, among other factors such as lack of parental supervision.

One study (Wong, 2011, in Masood \& Ali 2018) found that poverty was the main factor in problems related to divorce, single-parenthood and marriage. In the long run the economic factors caused 
criminal activities among adolescents in the affected families. Chesney-Lind and Sheldon's (2014) study in Canada found that girls were pushed by socioeconomic problems to get involved in gangs. Parental low income was found to lead them to depression and irritability causing them to adopt authoritarian approaches to children and sometimes beating up the children (Weatherburn et al., 1997 in Mishra \& Biswal 2018). The family economic status factor is also supported by Mbende et al. (2016) who argued that social, economic and cultural conditions prevailing in a country are some of the drivers of delinquency. Researchers have also noted that the structure of a family, whether compact, single or divorced, had an impact on the behaviour of the children in that family. The discussion now focuses on study findings pertaining to the family structure.

\section{FAMily STRUCTURE}

Poduthase (2012) found that single parenthood resulted in poor parental supervision resulting in juveniles becoming susceptible to antisocial behaviour. Ncontsa and Shumba's (2013) study attributed indiscipline among learners to disrupted homes, among other factors. Rathiabalan and Naaraayan's (2017) study concluded that being a single parent was one of the important risk factors for juvenile delinquency. Ardoin and Barthing's (2010) study found that children who were exposed to many delinquent factors such as absentee parents, domestic violence, alcohol and drug use in the family, poverty and incarcerated parents tended to be involved in violent crimes. Agarwal (2018) posited that broken families were directly related to higher rates of delinquency. Ullman's (1981) study found that all the boys in the study who lived with a step mother ran away from home. Sixty-six percent of boys who lived with a step- father ran away, and thirty-three percent of those who lived with the mother only ran away. Sixty-six percent of the boys who lived with their father only ran away. Hulela and Matsolo's (2011) study found that secondary school children who showed deviant behaviour were staying with foster parents. Research findings stated above affirm similar findings and conclusions drawn from studies conducted by Garegae (2007), and Matsoga (2003) regarding how family structure affects juvenile delinquency. Thus, being raised by people who are not one's real parents seems to negatively impact the growing adolescent.

\section{FAMily CONTROL/SUPERVISION}

The supervision of juveniles as they mature to adulthood is critical to ensure that they do not get swept away by various forms of delinquent conduct. Parents therefore need to have a firm grip on the conduct of their children. However, it has been found that advanced paternal age and maternal employment militate against a parent's effective supervision of the adolescent children who are full of energy and are adventure-seeking (Poduthase, 2012). Thus, close supervision, both at home and at school curtails an adolescent's criminal behaviour (Sahmey, 2016). These findings dove-tail with Chowdhurry et al'. s (2016) study which revealed that lack of proper family control contributed to delinquency among the youths, (Hulela \& Matsolo, 2011). Lack of parental control and antisocial behaviour of parents was found to lead to the development of criminality in the child (Henggler, 1989; Wright \& Wright 1994, in Mishra \& Biswal, 2018). Similarly, Uddin's (1995) study in Bangladesh found that family control and relationship were important factors in the occurrence of delinquency. In an overview of studies on risk factors for delinquency, Shader (2003) emphasizes that poor parental supervision was the strongest predictor of juvenile delinquency. In her study in New Zealand, Panich (2013) found that offending was correlated with family stress and deviant beliefs. She argued that parents whose children were deviant were likely to be applying inconsistent discipline and poorly monitored their children; such parents were exposed to stressors. Panich also posits that aggression was also found to be associated with poor parental monitoring and inconsistent discipline. Agnew (1992) concurs that poor relationships between children and their parents was one of the factors related to delinquency. Rathiabalan and Naaraayan (2017) found that punitive parenthood was a significant protective factor although the result surprised the researchers because it did not support previous research which did not confirm punitive punishment as a protective factor. This is an interesting finding but perhaps the explanation for the result could be explained by the fact that children were deterred from delinquent conduct because they wanted to avoid the unpalatable consequences which would befall them if they got involved in delinquent behaviour.

A permissive home environment can have a negative influence on a learner's behaviour according to Van Wyk (2001) in Semali and Vumilia (2016). Schoen and Nolen (2004) in Semali \& Vumilia (2016) also argue that many learners with disruptive behaviour come from homes which lack familial support structures and fail in their role to bring up well behaved children. A survey on the influence of 
the family on juveniles carried out by Iravani (2012) showed that a better family condition could help reduce juvenile delinquency, parents were hence supposed to play an important role through improved consultations with their children. The argument is further supported by Agarwal (2018) who observed that parental control to deal with juvenile crime is now weak. He further argued that primary socialization through the family, peer groups, traditional neighbourhood ties and close kin circles was becoming ineffective in India. Starker's (1966) study expressed similar views when he said that the father's firm discipline and mother's supervision tended to prevent delinquency. Wilson (1980) in Umezinwa \& Elendu (2012) found that parents who lacked in discipline and supervision were likely to have delinquent children than those who demonstrated strict discipline. The same view is shared by Shakya et al. (2012) who found that an adolescent's probability of drinking to the point of drunkenness and smoking were reduced by 57 percent and 43 percent respectively if the parents used an authoritative approach to parenting.

\section{CONCLUSION}

The family is the key social institution that provides the nurturing socialization of young children. The assumed relationship between delinquency and family life is critical today because the traditional American family is rapidly changing. It has become a thing of the past. Today, it seems much more of child-rearing is delegated to nannies, baby-sitters, and day care providers. Despite these changes, many families are able to adapt and continue functioning as healthy and caring units. But some families crumble under the chaotic stress, severely damaging the present and future of their children. It is obvious that the family cannot totally control outside influences upon its members, but it can have a significant impact on shaping the extent to which children are exposed to other major agents of socialization. The connection seems self-evident because a child is first socialized at home and from the beginning learns values, beliefs, and behaviors from parents and other family members. Any disjunction in an orderly family structure could have a significant, negative impact on a child's life. Despite good intentions, it is simply more difficult for one parent to provide the same degree of control, discipline, and support as two. Therefore, a broken home can be a strong determinant of a child's law-violating behaviour. The development of children thus greatly influences their future character and the likelihood of them engaging in delinquent acts. Last and not least, it is very important to encourage the formation public policies that support the family as a qualitative space for communication and affective relationships, with all that, there is urgent need of relevant strategies on child protection with specific focus on preventing child abuse, negligence among others.

\section{REFERENCES}

[1] Agarwal, D. F. (2018). Foundation for a general strain theory of crime and delinquency. Criminology, 30, 47-87

[2] Agnew, R., Matthews, S.K., Bucher, J., Welcher, A.N., Keyes, C. (2008). Socioeconomic status, economic problems, and delinquency. Youth and Society, 40, 159-181.

[3] Ardoin, M. and Barthing L. K. (2010). Deviant behaviour: A social learning approach. Belmont CA: Wadsworth Publishing Co.

[4] Alnasir, F.A. \& Al-Falaij, A.A. (2016).Factors Affecting Juvenile Delinquency in Bahrain. Journal of General Practice, 229.doi:10.4172/2329-9126.100229

[5] Chesney-Lind, S. and Sheldon, C. L. (2014). Self-control, peer relations and delinquency. Justice Quarterly, 22(4) 89-106.

[6] Chowdhurry, I.A., Khan, M.M. \& Uddin,I.(2016) Causes and Consequences of Juvenile Delinquency in Bangladesh: A Sociological Analysis. International Journal of Science Tomorrow Vol.1 No.4.

[7] Hoisko, S. \& Matsolo, K. (2011). How to overcome bullying at school? - The adult survivors' perspective. International Journal of Academic Research in Business and Social Sciences, 2(11): 58-72.

[8] Iravani, M.R. (2012). A social work study on juvenile delinquency. Management Science Letters 2 14031408 Growing Science Ltd.

[9] Mapp, R. (2009). The Role of Religiosity and Spirituality in Juvenile Delinquency. The College of New Jersey, Spring 2009.

[10] Mark, S. Andrew, D.\& Rose, R. (2007) Learner indiscipline in Schools. Review of Arts and Humanities.Vol.3, No. 2 pp.79-88

[11] Masood, S. \& Ali, S.M. (2018). Role of Family, Neighbourhood and Peers in Development of Delinquent Behaviour in Adolescents. Peshwar Journal of Psychology and Behavioural Sciences, Vol.4, No. 2, 17119 
[12] Mbende. R. Mishra, E. \& Biswal, R. (2018). Parental imprisonment: Effects on boys' antisocial behaviour and delinquency through the life course. Journal of Child Psychology and Psychiatry, 46 (12): 1269-1279.

[13] Mishra, E. \& Biswal, R. (2018). Trends and Factors Associated with Juvenile Delinquency: a Study from India. International Journal of Applied Social Science. Volume 5 (10), October (2018): 1613-1625

[14] Ncontsa, V.N. \& Shumba A. (2013). The nature causes and effects of school violence in South African high schools. South African Journal of Education 33 (3).

[15] Poduhase, J. W. (2012). Family and Personality factors in Juvenile delinquency. Master of Arts in Psychology thesis. University of Canterbury, New Zealand.

[16] Rathiabalan, C.H. \& Naarayan, A. (2017). Juvenile Delinquency: Cause and Effect. Yale: New Haven Teachers Institute.

[17] Roberts, T. V. (2013). Beliefs about what works in juvenile rehabilitation. Criminal Justice and Behaviour, 36(2): 184-197.

[18] Sahmey, K. (2013). A Study on Factors Underlying Juvenile Delinquency and Positive Youth Development Programs. Master of Arts in Development Studies Dissertation. National Institute of Technology. Odisha, India.

[19] Semali, C. \&Vumilia, L.K. (2016). The relationship between childhood maltreatment and adolescent involvement in delinquency. Criminology: 33(4): 451-481.

[20] Shakya, H.B., Christakis, N.A. \& Fowler, J.H. (2012). Parental Influence on substance use in Adolescent. Social Networks Arch Pediatr Adolesc Med.2012Dec; 166(12): 132-1139. doi: 10.1001/archpediatrics. 2012.1372.

[21] Simos, M., Sladky, T.J., \& Kang, W, C. (1991) "Easy access to the census of Juveniles in Residential Placement". http://www.ojjdp.gov/ojstatbb/ezacjrp/ (retrieved 15/07/15.)

[22] Thornberry, R. (1991). (The lack of professional knowledge in values education, Teaching and Teacher Education. An international Journal of Research and Studies, 2008 (24), 7, 1791-1798.

[23] Uddin, B. S. (1995). Delinquency and justice: Amazon: McGraw Hill College.

[24] UNESCO (2014). Risk Factors for delinquency among Canadian Youth: Currrent Knowledge and future directions. Ottawa: UNESCO.

[25] Wilson, M. (1980). Do delinquency and community violence exposure explain internalizing problems in early adolescent gang members? HHS Public Access, 4(3): 1-8.

Citation: Philip Gazimbe \& Tungu Mufunani Khosa. " The Role Played by the Family in Contributing or Abating Juvenile Delinquency in Schools" International Journal of Humanities Social Sciences and Education (IJHSSE), vol 8, no. 7, 2021, pp. 127-132. doi: https://doi.org/10.20431/2349-0381.0807015.

Copyright: (C) 2021 Authors. This is an open-access article distributed under the terms of the Creative Commons Attribution License, which permits unrestricted use, distribution, and reproduction in any medium, provided the original author and source are credited. 